\title{
O DISCURSO IDEOLÓGICO-NACIONALISTA EM CARTILHA DISTRIBUÍDA PELO EXÉRCITO DO RS DURANTE O PERÍODO DITATORIAL NO BRASIL
}

\author{
João Paulo Massoti ${ }^{1}$ \\ Silvia Niederauer ${ }^{2}$
}

\begin{abstract}
Resumo: Este artigo se propõe a pensar a Ditadura Militar brasileira e a reprodução do seu pensamento ideológico através do estudo do discurso na Carta a um recruta entregue aos jovens em idade para o alistamento militar no ano de 1968 no Estado do Rio Grande do Sul. Escrita pelo Ten. Cel. Jonas Correia Neto e expedida pelo Ministério do Exército sob a supervisão e coordenação da Secretaria de Educação e Cultura - Coordenação de Educação Moral e Cívica do RS, a carta possui uma voz paternal que se propõe a mostrar ao jovem que o melhor caminho a seguir é o da ordem e da obediência. Para pensar ideologia será elaborada uma construção conceitual baseada no estudo das realidades vividas pela sociedade no contexto histórico geral (a ditadura), visando compreender as inúmeras incoerências presentes na carta (discurso militar), a fim de atenuar ou minimizar as arbitrariedades cometidas em nome do Estado. O estudo proposto apresenta aporte teórico a partir da concepção de ideologia de autores como Slavoj Zizek e Sigmun Freud que discorrem sobre o modo inconfesso de servir algum interesse particular de poder.
\end{abstract}

Palavras-chave: Ditadura Militar Brasileira. Ideologia. Cartilha.

Abstract: This article proposes to think the Brazilian Military Dictatorship and its reproduction of ideological thought in the speech of the study on Carta a um recruta given for young people in age for military conscription in the year of 1968 in the state of Rio Grande do Sul. Written by Lieutenant Coronel Jonas Correia Neto and issued by the Army Ministry under the supervision and coordination of the Department of Education and Culture Coordination of Moral and Civic Education of the State of Rio Grande do Sul - Brazil, the letter has a paternal voice that proposes to show the young people that the best way to follow is the order and obedience. To think the ideology it will elaborate a conceptual construction based on the study of the realities experienced by society in general historical context (the dictatorship), to understand the numerous inconsistencies present in the letter (military speech), in order to mitigate or minimize the arbitrary acts on behalf of State.The proposed study presents theoretical conception for ideology from of authors such as Slavoj Zizek and Sigmun Freud who talk about the unspoken way to serve a particular interest in power.

Keywords: Dictatorship Brazilian Military. Ideology. Guidebook.

\footnotetext{
${ }^{1}$ Mestre em Letras - URI Câmpus FW. E-mail: joaomassotti@yahoo.com.br.

${ }^{2}$ Doutora em Letras - URI Câmpus FW. E-mail: silvia.niederauer@yahoo.com.
} 
"O silêncio do cortejo permitia que se ouvisse a impaciência do inimigo que os esperava a alguns metros: era aquele mesmo ruído de cascos de cavalos que antes chegava ao altar e agora estava cada vez mais próximo" (VENTURA, 2013).

\section{Introdução}

Em seu ensaio "O espectro da ideologia", Slavoj Zizek (1999) aborda as relações de ideologia partindo da desconstrução do seu conceito propriamente dito para propor a existência de um paradigma que visa explicar que não há maneira de fugir de um pressuposto ideológico, senão pela criação de outro, esteja ele sobre o ponto de vista político, social ou religioso. Zizek parte do pensamento lacaniano propondo que a ideologia engloba tudo o que fazemos podendo designar qualquer coisa

uma atitude contemplativa que desconhece sua dependência em relação à realidade social, até um conjunto de crenças voltado para a ação; desde o meio essencial em que os indivíduos vivenciam suas relações com uma estrutura social até as ideias falsas que legitimam um poder político dominante. Ela parece surgir exatamente quando tentamos evitá-la e deixa de aparecer onde claramente se esperaria que existisse. "Quando um processo é denunciado como ideológico por excelência" (ZIZEK, 1999, s.p.).

Isso significa que um indivíduo estará sempre preso a uma determinada concepção ideológica, sendo necessário que haja outro corpo de opiniões, para que dele possa distinguir a sua própria postura. De acordo com o autor, a ideologia pode ser dividia em três modos conceituais, aquele que a entende como um conjunto de ideias e crenças; aquele que considera sua existência material e sua disseminação por meio de instrumentos institucionais; e aquele que relativiza seu alcance na sociedade.

Os conceitos apontados pelo autor procuram estruturar e classificar os mais variados tipos de organizações sociais que são sustentadas a partir dos princípios ideológicos. Para o autor, a ideologia não é falsa em sua essência, pois ela pode responder a conteúdos verdadeiros, uma vez que o que realmente importa é o modo como o conteúdo irá se relacionar com a postura subjetiva envolvida em seu próprio processo de enunciação. O que se observa no texto, é que toda a ideologia detém o poder de dominação de caráter social, em uma relação de poder versus exploração. 
Nessa perspectiva, o poder se mantém velado, uma vez que, "é muito mais fácil mentir sob o disfarce da verdade" (ZAZUK, 1999, p. 14).

Esse tipo de pensamento fica bastante elucidado quando se pensa nos crimes cometidos durante o período ditatorial, em busca de uma "verdade", sobre o capuz da tortura. Com a justificativa de estarem livrando o país da ameaça comunista, os militares torturavam, matavam, e negligenciavam os corpos das vítimas, como forma de, através do medo, esconder o clima de repressão e autoritarismo daqueles que, alheios aos fatos, estavam mergulhados no aparato ideológico difundido em meio ao cidadão comum.

\section{Carta a um recruta, disciplina e ideologia}

Há 52 anos a ditadura midiática-civil-militar foi instaurada no Brasil através de um golpe de Estado. A repressão, resultado do golpe, iria se prolongar até 1985 quando foi reinstaurada a democracia no país. Durante este período (1964-1985) os militares procuraram manter e reforçar seu discurso de forma hegemônica, inviabilizando quaisquer manifestações contrárias a suas ideologias. As leis da força e da mordaça, legitimadas através da censura e da tortura, dominaram abertamente o país voltando-se contra os opositores do regime.

Somado a isso, eram utilizadas propostas que exaltavam o país, tendo como objetivo a formação de um cidadão nacionalista e patriota. Era comum aos militares utilizar técnicas que disfarçavam o regime através de eufemismos às práticas repressivas, bem como empregar aos meios de comunicação - jornais, rádio e televisão - propagandas político-ideológicas enaltecendo o Estado em favor do cidadão. Além disso, ao lado das tantas propagandas vinculadas, também figuravam o uso de panfletos, cartas, manuais didáticos e discursos que ajudavam a produzir a imagem que o governo necessitava.

Conforme Schwacz e Starling (2015) a Assessoria Especial de Relações Públicas (Aerp), fez funcionar uma campanha de propaganda política sem precedentes.

A propaganda feita pela Aerp era criativa, não tinha nada de chapabranca nem ostentava sinais típicos do marketing político. As peças falavam em otimismo, orgulho e grandeza nacional; celebravam a 
diversidade e a integração racial brasileira; afirmavam a harmonia social (SCHWARCZ; STARLING, 2015, p. 454).

À frente da Aerp, Hernani d'Aguiar produziu campanhas com o intuito de estimular e enaltecer o país de maneira ufanista, mostrando, conforme Fico (2003), um "Brasil Grande", e com um governo forte e empreendedor. Para desviar a atenção do público da imagem negativa de país que se tinha até então, foram propostas iniciativas através de, por exemplo, "concursos de estudantes ou da promoção de eventos" (FICO, 2003, p. 195), o que criava uma espécie de cidadania decorativa, na qual o cidadão precisaria apenas lembrar-se de enaltecer o Estado.

No exército, àqueles que estavam em idade para o engajamento, o clima era o mesmo. Era preciso legitimar ainda mais a ideia de que havia a necessidade de doar-se à nação garantindo a segurança do país, e protegendo as instituições e os cidadãos das investidas comunistas. Assim, meras construções de uma ideologia nacionalista, os jovens eram submetidos às ações disciplinares que procuravam direcionar suas opiniões acerca do contexto, tornando-as maleáveis.

Freud (2011) aponta para a possibilidade de distinguir espécies diferentes de massas, passageiras e duradouras. Massas homogêneas que são compostas de indivíduos do mesmo tipo, e não homogêneas, além das massas naturais e artificiais, que são aquelas que requerem uma coação externa para se manter, como por exemplo, a igreja e o exército, dois tipos de massa dentre mais bem organizadas. Nesses casos, conforme o autor, não se pergunta, nem é dado a alguém a escolha sobre o desejo ou não de ingressar numa dessas massas, uma vez que a própria tentativa de desligamento é desestimulada, severamente punida, ou condicionada a situações bem determinadas.

Tanto na igreja, quanto no exército, por mais diferente que sejam, prevalece a mesma simulação de que há um chefe supremo - Cristo e um general - que ama com o mesmo amor todos os indivíduos da massa. É essa a ilusão que precisa ser mantida. De acordo com Freud (2011) a ligação de indivíduos ao Cristo, pai, também pode ser vista como algo parecido no exército em que

o general é o pai, que ama igualmente todos os seus soldados, e por isso eles são camaradas entre si. O Exército se diferencia estruturalmente da Igreja pelo fato de consistir num escalonamento 
desse tipo. Cada capitão é como que o general e o pai de sua companhia, cada suboficial, de sua unidade (FREUD, 2011, p. 36).

É, portanto, razoável que a maneira encontrada por Correia Neto, a introduzir suas ideias aos soldados em "Carta a um recruta" tenha sido "MEU FILHO" (CORREIA NETO, 1967, p.3). Somada a essa concepção ainda está o fato de que nela não há lugar para ideias contrárias à pátria, à glória nacional e outras que sejam coerentes ao discurso do Exército, de modo que negligenciar tais discursos podem desencadear protestos de indivíduos contra o papel que a ele é imposto pelo próprio Exército.

Em seu livro Vigiar e punir, Foucault aponta para o poder disciplinar, que tem a função de "adestrar" o outro se apropriando da massa, de modo que seja possível reduzi-la ou decompô-la em pequenas singularidades, necessárias à ordem. Para o autor, "discipline 'makes' individuals; it is the specific technique of a power that regards individuals both as objects and as instruments of its exercise (FOUCAULT, 1995, p. 170).Deste modo, o regime de poder disciplinar irá servir como um mecanismo para moldar o comportamento dos indivíduos.

A concepção foucaltiana, aponta para diferentes unidades disciplinares, as quais são expostos os cidadãos, como por exemplo, a igreja, a escola, a família e o exército, fazendo com que o corpo seja submetido a novas formas de poder que irão desarticulá-lo e corrigi-lo através de uma nova mecânica de poder. Graças à vigilância hierarquizada o poder disciplinar torna-se um sistema integrado, organizado de forma múltipla, automática e anônima, cujo funcionamento compreende uma rede de relações de alto a baixo, de baixo para cima e até lateralmente, sustentando um conjunto, perpassando os efeitos de poder que se apoiam uns sobre os outros em uma espécie de "supervisor perpetually supervise" (FOUCAULT, 1995, p. 177).

A cartilha escrita por Correia Neto descreve dois campos disciplinares, o exército e a família. Escrita em fevereiro de 1967 pelo Tenente Coronel Jonas Correia Neto e, distribuída no estado sobre a Coordenação de Educação Moral e Cívica (COMOCl/RS), a cartilha apresenta em sua narrativa, em primeira pessoa, uma voz extremamente paternalista, cuja disciplina militar se dará de forma permanente e de certo modo, intransigente, sobreposta à disciplina familiar, que 
considera o carinho, o respeito e o envolvimento de cada um no âmbito do espaço do lar

No Exército, Você sentirá a disciplina de uma forma permanente e até certo ponto intransigente, muito diversa daquela doce disciplina familiar, em que o carinho dos pais pode e deve sobrepor-se a todas as outras imposições. Isso talvez o aborreça, mas o hábito da obediência fará com que Você, subconscientemente, se prepare melhor para o futuro, para o dia em que tiver que chefiar (CORREIA NETO, 1967, p. 6).

Neste raciocínio percebe-se que um discurso que antevê a ruptura familiar a um espaço completamente novo, tende a carregar consigo a beleza da arte retórica que, neste caso intenta em minimizar essa separação que principia. No discurso de Correia, a obrigatoriedade do serviço militar é atenuada, quando são subvertidos os propósitos da obediência, pela justificativa subconsciente de uma espécie de meritocracia do poder, sobre a qual àquele que a pratica será recompensado com o status de autoridade.

A ordem era o ponto central do projeto social e político dos militares. E para mantê-la eram utilizados todos os meios coercitivos de repressão, o que incluia desde técnicas de doutrinação, a tortura àqueles que se mostrassem contrários aos princípios ideológicos impostos. Assim, o jovem seria instruído à obediência e a disciplina que deveriam ser seguidas, inclusive, como já mecionado, a uma possibilidade à promoção e ao merecimento "Quem vai mandar, tem que aprender a obedecer" (CORREIA NETO, 1967, p. 6). É evidente que, após certo tempo o individuo tome por ideal a instituição a qual pertence, por isso o discurso construído por Correia Neto é cheio de contradições. Enquanto o caos, a repressão e a censura imperavam no espaço urbano, o Tenente Coronel escrevia sobre um exército onde havia "mais ordem, mais organização, mais responsabilidade, mais sentimento do dever, mais respeito à condição humana, mais incentivo ao esforço, mais zelo pelos bens públicos, mais espírito de brasilidade" (CORREIA NETO, 1967, p. 13).

No Rio Grande do Sul, de 1968, ano do Al-5, a entrega da "Carta a um recruta", pela "Seção do Serviço Militar Regional 3, tinha exatamente propósito de explicar ao jovem em idade militar os porquês de sua participação na corporação e "desmitificar" as "inverdades" que subversivamente pudessem ser apontadas do lado 
de fora.Neste sentido a cartilha vai ao encontro do conceito de ideologia "em si" apresentado por Slavoj Zizek (1999), no qual ela é vista como uma doutrina ou um conjunto de ideias, crenças e conceitos que se destinam a convencer o outro de sua "veracidade", mas que de modo inconfesso, está servindo a algum interesse particular de poder.

O poder aqui está em imputar através de um texto, em forma de carta, os interesses sociais inconfessos à grande massa, encobrindo evidências e transformando a realidade. A começar pelo tom suave e discricionário dado às questões discriminatórias ocorridas no Brasil dos militares, "a discriminação é inadmissível! Neste País não pode haver tratamento diferente para militares e civis, para ricos e pobres, para claros e escuros, para letrados e analfabetos." (CORREIA NETO, 1967, p. 11-12); passando pela importância de se manter uma instituição militar em funcionamento, "o País que não possuir um Exército, como o nosso, estará sob permanente ameaça de desrespeito à sua soberania e à sua liberdade" (NETO, 1967, p. 11); e até mesmo utilizando termos muito presentes em regimes de repressão, como "disciplina e hierarquia" (NETO, 1967, p. 8), com objetivo de tornálos comuns ao cotidiano.

Julga-se interessante observar que diferentemente do que se faz crer no discurso da cartilha, os negros foram bastante perseguidos durante o período ditatorial. Manifestações de grupos como a União dos Homens de Cor (UHC) e o Teatro Experimental Negro (TEN) que desde a década de 1940 lutavam pelas causas dos negros no Brasil, ao questionarem, como tantos outros movimentos minoritários existentes durante o período ditatorial, a opressão e o autoritarismo, passaram a fazer parte do rol das entidades consideradas "subversivas". Além disso, para Kössling (2008), os governos militares, na tentativa de homogeneizar socialmente a população de forma "coesa", sem conflitos ou contestações ao poder vigente e aos seus projetos sociais, desconsideraram a possibilidade da afirmação de uma identidade afro-brasileira.

Todas essas considerações levam a perceber que em "Carta para um recruta" não suficiente em prescrever a conduta a ser adotada pelo seu leitor, configura ainda um conglomerado de contradições. A maioria tencionava dar legitimidade ao regime autoritário, inserindo em suas passagens, fragmentos que exaltavam a democracia e a igualdade entre os cidadãos, como por exemplo em,"Porque nosso 
Exército é de fato um Exército Democrático! Logo, a Lei do Serviço Militar que estabelece a obrigatoriedade da sua prestação é coerente com a letra e o espírito constitucional do Brasil: todos são iguais perante a Lei!" (CORREIA NETO, 1967, p. 10). Ao contrário do que propõe, o discurso apresenta valores pouco democráticos, participativos e transparentes, utilizando-se da lei, que aponta para a igualdade de direitos a todos os cidadãos, para justificar obrigação de servir à nação.

Além disso, a ideologia concebida no texto da cartilha, parte do conceito de Althusser (1985) que através de estudos ideologicamente marxistas tece considerações acerca das condições de produção da classe dominante no contexto do processo de formação das classes sociais. Em seu texto Ideologia e Aparelhos ideológicos do Estado, o autor define como sendo Aparelhos Ideológicos de Estado "um certo número de realidades que se apresentam ao observador imediato sob a forma de instituições distintas e especializadas" (ALTHUSSER, 1985, P. 43). Somado a isso, o autor propõe que

qualquer aparelho de Estado, seja ele repressivo ou ideológico, $<<$ funciona >> simultaneamente pela violência e pela ideologia [...] 0 Aparelho (repressivo) de Estado funciona de uma maneira massivamente prevalente pela repressão (inclusive física), embora funcione secundariamente pela ideologia [ou vice versa][...] o Exército e a Polícia funcionam também pela ideologia, simultaneamente para assegurar a sua própria coesão e reprodução e pelos valores que projetam no exterior (ALTHUSSER, 1985, p. 46-47).

Durante a ditadura militar era importante que o outro (cidadão) fosse mantido distante de qualquer inserção no campo de visão do cotidiano militar, de modo que ao público eram revelados apenas aspectos de caráter formal como, por exemplo, a participação do Exército e da Polícia em desfiles comemorativos às datas cívicas. Aliás, estas sempre foram muito utilizadas durante a repressão. A postura, o hino, o silêncio e amor à pátria deveriam fazer parte de um ideal comum a ser seguido, nunca criticado.

Isso pode ser percebido na cartilha escrita por Correia Neto, em que estes ideais se sobressaem quando o autor menciona não ser lícito ao militar "tornar-se voluntariamente passível de críticas fundadas: [já que] o seu mau procedimento não afetará a ele somente, antes se refletirá em toda a Corporação, salpicando-a, manchando-a, reduzindo-lhe a reserva moral" (CORREIA NETO, 1967, p. 11- 
12). Esta formalidade que servia como uma aparência externa e, que no momento do engajamento, necessitava ser ainda mais estigmatizada, oportunizava um tipo de formação moral e cívica ainda mais ideológica.

Evidencia-se assim, a importância da mídia como recurso para instalar o universo ideológico na memória dos indivíduos. O discurso funda a ideologia, a ideologia se funde ao indivíduo de modo que, ao submeterem os jovens e a população um discurso cívico-nacionalista, os militares exaltavam não apenas o país, mas disciplinavam as mentes e os corpos, de crianças e jovens que, mais tarde, estariam prestando continência aos seus superiores. A ditadura militar criou uma fantasia ideológica permitindo aos militares todo o tipo de violência em nome da ordem, sem que a população, ou até mesmo os próprios militares responsáveis por toda a violência fossem condenados ou se sentissem culpados.

Por meio do seu repertório discursivo, verifica-se, portanto, que Correia Neto, compôs uma narrativa contraditória e incoerente com os acontecimentos da época. Percebe-se que os militares e seus adeptos, embora soubessem da repressão, a ignoravam em prol de um bem maior, a nação. Assim, entende-se que o estigma da violência presente na maior parte da cartilha não pode continuar silenciado, uma vez que, longe de promovê-lo, tornar público um discurso incoerente e indiferente a toda violência sofrida, é garantir a voz daqueles que foram enganados resgatando-Ihes a outra face da história.

\section{REFERÊNCIAS}

ALTHUSSER, Louis. Aparelhos ideológicos de estado: Nota sobre os aparelhos ideológicos de estado. 3 ed. Rio de Janeiro: Graal, 1985.

CORREIA NETO, Jonas. Carta a um recruta. Rio Grande do Sul, Secretaria de Educação e Cultura, 1967.

FICO, Carlos. Espionagem, polícia política, censura e propaganda. Os pilares básicos da repressão. In: FERREIRA, Jorge \& DELGADO, Lucilia de Almeida Neves (Org.). O Brasil Republicano. O tempo da ditadura. Regime militar e movimentos sociais em fins do século XX. 1. ed. Rio de Janeiro: Civilização Brasileira, 2003. 
FREUD, Sigmund. Duas massas artificiais: igreja e exército [1921]. In: Psicologia das massas e análise do eu e outros textos (1920-1923). Tradução e notas Paulo César de Souza. São Paulo, Companhia das Letras, 2011. 